\title{
Measuring quality of life in women undergoing surgery for breast hypertrophy
}

\author{
Carolyn L Kerrigan MD ${ }^{1}$, Gaston Schwarz MD², Roland Charbonneau MD² \\ ${ }^{1}$ Section of Plastic Surgery, Dartmouth Hitchcock Medical Center, Lebanon, New Hampshire, USA; \\ ${ }^{2}$ Division of Plastic Surgery, Royal Victoria Hospital, McGill University, Montreal, Quebec
}

\section{Kerrigan, G Schwarz, R Charbonneau. Measuring quality of life in women undergoing surgery for breast hypertrophy. Can J Plast Surg 2001;9(6):221-225.}

The purpose of the present study was to describe the outcomes associated with reduction mammaplasty in terms of physical parameters and health-related quality of life. A prospective cohort study was designed and included women undergoing bilateral breast reduction surgery at the Royal Victoria Hospital, Montreal, Quebec, who consented to participate. Women were evaluated preoperatively for symptoms, physical parameters, quality of life (Short Form [SF]-36 and Multidimensional Body Self Relations Questionnaire [MBSRQ]) and general demographic characteristics that were identified as potential confounders. Postoperatively, women were re-evaluated at six months for symptoms, physical parameters and quality of life.

A total of 74 women were entered in the study. Their average age was 32.3 years, and the mean mass of resected volume per breast was $630 \mathrm{~g}$. There was a statistically significant improvement in symptoms six months after surgery $(\mathrm{P}<0.05)$. There was also a statistically significant improvement in the physical component summary scale of the SF-36 and several additional subscales: bodily pain, physical functioning, role-physical, and vitality. The MBSRQ subscale of appearance evaluation was significantly increased (2.69 compared with $3.12, \mathrm{P}=0.000$ ), whereas the appearance orientation subscale was unchanged. The amount of tissue removed did not appear to correlate with the change in physical symptoms or health-related quality of life resulting from the surgery.

This study showed significant improvement in physical and psychological aspects of health-related quality of life in women undergoing reduction mammaplasty.

Key Words: Breast hypertrophy; Health-related quality of life; Outcomes; Reduction mammaplasty

\section{Mesurer la qualité de vie des femmes opérées pour réduction mammaire}

RÉSUMÉ : Le but de la présente étude était de décrire le pronostic des interventions pour réduction mammaire sur le plan des paramètres physiques et sur le plan de la qualité de vie reliée à la santé. Une étude de cohorte prospective a été conçue et a regroupé des femmes devant subir une réduction mammaire bilatérale à l'Hôpital Royal Victoria de Montréal, au Québec, qui ont consenti à participer. Les femmes ont été évaluées avant l'opération pour ce qui est des symptômes, des paramètres physiques, de la qualité de vie (Short Form [SF]-36 et Multidimensional Body Self Relations Questionnaire [MBSRQ]) et sur le plan des caractéristiques démographiques qui ont été identifiées comme facteurs de confusion potentiels. Six mois après l'intervention, les femmes ont de nouveau été évaluées sur le plan des symptômes, des paramètres physiques et de la qualité de vie.

En tout, 74 femmes ont été inscrites à l'étude. Elles avaient en moyenne 32,3 ans et la masse moyenne de volume réséqué a été de 630 g par sein. On a noté une amélioration statistiquement significative des symptômes six mois après l'intervention $(\mathrm{p}<0,05)$. On a également noté une amélioration statistiquement significative de la composante physique à l'échelle d'évaluation sommaire du SF-36 et de plusieurs autres sous-échelles : douleurs physiques, rôle physique et vitalité. La sous-échelle du MBSRQ ayant trait à l'évaluation de l'aspect physique avait significativement augmenté $(2,69$, contre $3,12, \mathrm{P}=0,000)$, alors que la sous-échelle des l'aspect physique est restée inchangée. La quantité de tissu éliminé n'a pas semblé être en corrélation avec le changement des symptômes physiques ou la qualité de vie reliée à la santé résultant de la chirurgie.

\footnotetext{
This paper was presented in part at the American Association of Plastic Surgeons Annual Meeting, Portland, Oregon, USA, May 18 to 21, 1997 and the Canadian Society of Plastic Surgeons Annual Meeting, Calgary, Alberta, May 21 to 24, 1997

Correspondence: Dr Carolyn L Kerrigan, One Medical Center Drive, Lebanon, New Hampshire 03756, USA. Telephone 603-650-5881,

fax603-650-5809, e-mail carolyn.l.kerrigan@hitchcock.org
} 
A dvancements in outcomes research have produced tools to objectively document the impact of medical interventions on health-related quality of life (HRQL). Reduction mammaplasty has long been performed for the correction of symptoms associated with macromastia and for psychosocial reasons. The most common physical symptoms include bra strap groove pain, shoulder pain, upper back pain, neck pain, lower back pain and intertrigo. From the psychosocial perspective, women most frequently report feeling uncomfortable about their bodies, having difficulty finding clothes that fit, and the inability to run and participate in sports (1). Despite previous studies documenting that surgical reduction of breast size alleviates the physical symptoms and psychosocial complaints in a large percentage of patients and that overall patient satisfaction is very high (2-4), the cost-benefit ratio of this procedure will be under increased scrutiny as resource allocation is reconsidered during this time of fiscal restraint.

It is often anecdotally suggested that correction of macromastia is purely a cosmetic procedure and should not be covered by health insurance. In Canada, some provinces dictate a minimum resection weight per breast, some provinces require submission of photographs to a provincial review panel, and other provinces leave the decision entirely up to the surgeon and patient. In the United States, the process of utilization review is highly variable from one third party payer to another. Some insurance companies do not cover this surgery, other insurers require the presence of three of the four most common symptoms, other insurers require minimum resection weights of 350 to $500 \mathrm{~g}$ and other insurers exclude patient eligibility on the criteria of obesity. Still, other insurance companies require the surgery to be 'medically necessary'; however, medically necessary has not been clearly defined. In an attempt to resolve some of these issues, Schnur et al (5) proposed a cut-off level based on body surface area and weight of unilateral resection. Using the results of a mail survey of plastic surgeons, they concluded that women who fell below the fifth percentile were motivated by purely cosmetic reasons and those falling above the 22nd percentile were motivated by purely medical reasons. In Sweden, the issue of who gets surgery for breast hypertrophy has been handled by developing a priority system based on age, breast volume, subjective symptoms, weight and asymmetry (6).

There appears to be no scientific rationale for this debate because no studies exist that relate benefits of surgery to preoperative symptom severity, grams of tissue resected or body weight. The question raised by these inconsistent utilization review processes is whether the benefits of reduction mammaplasty are significantly associated with the weight of the resected breast tissue or body weight.

A key element in addressing this issue is a valid and reliable outcome measure that describes the benefits associated with reduction mammaplasty. Outcome measures based on strictly physical manifestations of disease or aspects of health capture only one component of well being. Psychological and social aspects have been recognized as being equally important, as is stated in the World Health
Organization definition of health as physical, social and psychological well being (7). This multidimensional conceptualization of health has been gaining wide acceptance and outcome measures describing these dimensions of health are routinely used in clinical research (8). HRQL has been used to describe these dimensions of health collectively.

With respect to the quality of life evaluation in the context of reduction mammaplasty surgery, a search of the literature at the initiation of our study failed to identify any validated instrument used in this patient population. Publications since 1996 have reported on generic measures of general health status in these women. One such measure is the Short Form (SF)-36 that has been used in several studies to characterize women before and after reduction mammaplasty (9-12). The SF-36 is a widely used and validated instrument that takes patients about $10 \mathrm{~min}$ to complete. The SF-36 reports HRQL on several subscales: physical function, role-physical, role-emotional, social, mental health, pain, energy, and health perception.

Interviews with women with large breasts indicate that they may have received unwanted comments about their breasts, and often have developed some embarrassment, self-consciousness and shyness $(3,4)$. In searching for possible instruments for use in this population to capture a woman's self-image, the Multidimensional Body Self Relations Questionnaire (MBSRQ) was chosen (13). This is a self-report questionnaire that has been well validated in many different populations. It contains seven subscales, two of which, appearance evaluation and appearance orientation, were deemed to be particularly relevant to women with breast hypertrophy.

There are no available validated instruments to measure the condition-specific impact of breast hypertrophy and its treatment. Although several authors have used questionnaires that capture the most common symptoms of breast hypertrophy, none have been subjected to standard psychometric analysis. For the purpose of this study, previous questionnaires were adapted to capture breastspecific symptoms.

The main purpose of the present study was to explore the description of outcomes in this patient population. Our key objectives were to describe the outcome associated with reduction mammaplasty in terms of physical parameters and quality of life, and to identify the determinants of these outcomes.

\section{PATIENTS AND METHODS}

All patients referred for bilateral reduction mammaplasty to the Plastic Surgery Division of the Royal Victoria Hospital, Montreal, Quebec, were potentially eligible for entry into the study. There were no exclusion criteria. The study was approved by the Research Ethics Board of the hospital. Approximately 100 breast reductions are performed at the Royal Victoria Hospital annually. An $80 \%$ participation rate was anticipated. Patient recruitment was planned over a one-year period. 


\section{Study design}

A prospective cohort study was designed. Eligible patients who consented to participate in the study underwent reduction mammaplasty surgery, as described below. Patients who were entered in the cohort were evaluated at baseline before surgery and six months after surgery by using a collection of validated and new, unvalidated instruments. In addition, basic demographic data, surgical data and postoperative complications were systematically recorded. The main questionnaires were administered at the baseline and six-month postoperative evaluations.

\section{Treatment}

Women were first evaluated in the office by their surgeon, and the decision regarding suitability for surgery was made. Baseline preoperative physical parameters were recorded by the surgeon, and patients completed the baseline selfadministered questionnaire. The physical parameters included bra size, weight, height and sternal notch to nipple distance. The reduction mammaplasty was subsequently performed using the technique of preference of the surgeon, and this technique was recorded as part of the data collection. Routine postoperative follow-up visits were scheduled at three weeks, six weeks, three months and six months.

\section{Self-administered questionnaire}

The patient self-administered questionnaire was a compilation of demographic questions, a questionnaire on reasons for undertaking surgery and subjective complaints, each developed specifically for this study. In addition, the validated and widely used SF-36 (14-16) and MBSRQ (13) were included.

The questionnaire on reasons for undertaking surgery used a Likert scale, and women were asked to rate 10 items. The subjective experience of neck pain, back pain and shoulder grooves was measured using visual analog scales. This questionnaire consisted of an empirical set of questions that had not yet been subjected to the rigors of validation but was similar in content to that used by other investigators $(5,12,17)$. Patients completed a self-administered questionnaire about symptom frequency using a rating based on a five-point Likert scale where a score of 1 indicated that a symptom had not occurred during the past week and 5 indicated that the symptom had occurred daily during the past week.

\section{Statistical analysis}

The pre- to postoperative change in outcome was assessed for statistical significance using paired $t$-tests. Emphasis was placed on volume resected because this is the criterion considered to be the limiting parameter for insurance by the Quebec government.

\section{RESULTS}

A total of 74 women were recruited into the study. At the six-month follow-up period, 51 women were interviewed but only 38 provided adequate data for full analysis.

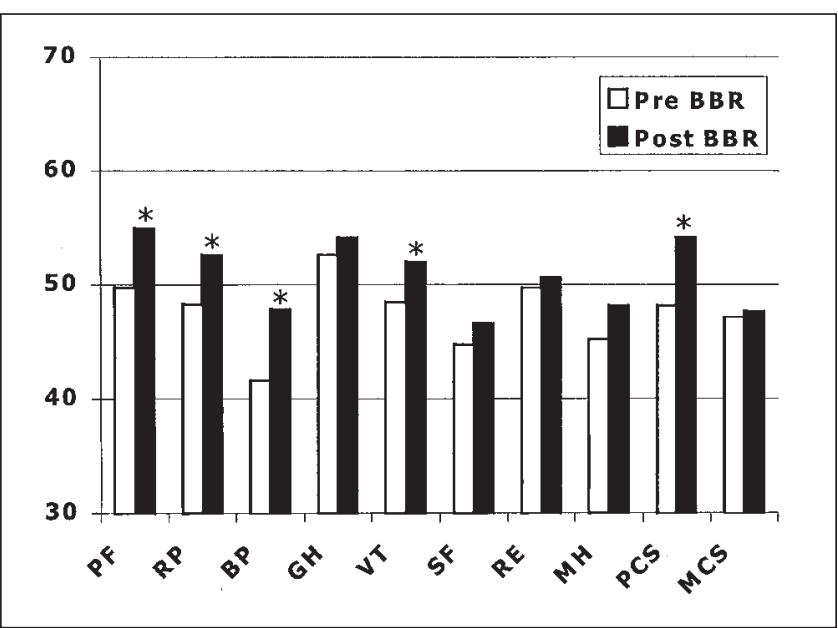

Figure 1) Norm-based Short Form-36 scores before $(n=61)$ and after $(n=38)$ breast reduction. *Statistically significant change as measured by unpaired $\mathrm{t}$-test. Both paired and unpaired $\mathrm{t}$-tests were computed and they did not show differences in significance. BBR Bilateral breast reduction; BP Bodily pain ( $P=0.0004)$; GH General health; MCS Mental component summary; MH Mental health; PCS Physical component summary $(P=0.0004)$; $P F$ Physical function $(P=0.000)$; RE Role-emotional; RP Role-physical ( $P=0.019) ; S F$ Social functioning; VT Vitality $(P=0.033)$

\section{Demographics}

The mean age of the study participants was 33.24 years (range 18 to 66 years, $\mathrm{SD} \pm 12.1$ ), their mean height was $163.32 \mathrm{~cm}(\mathrm{SD} \pm 6.20)$, their mean weight was $72.6 \mathrm{~kg}$ $(\mathrm{SD} \pm 30.9)$ and mean body mass index (BMI) was $27.54 \mathrm{~kg} / \mathrm{m}^{2}(\mathrm{SD} \pm 5.42)$. The median preoperative bra band and cup sizes were 38 and D, respectively, and postoperatively were 36 and $C$, respectively. The mean weight of resection per breast was $636 \mathrm{~g}$ for the left breast and $645 \mathrm{~g}$ for the right breast. Of the 51 patients who completed the sixmonth follow-up interview, a comparison of preoperative weight (mean $73.4 \mathrm{~kg}$ ) to postoperative weight (mean $72.1 \mathrm{~kg}$ ) showed no significant change.

\section{Reasons for surgery}

A woman's decision to have surgery was 'very' influenced by reasons such as how well clothes fit $(43.6 \%)$, back pain (31.6\%), other people's perception $(27 \%)$, neck stiffness $(26.3 \%)$, improvement in posture $(26.3 \%)$, neck pain $(25.6 \%)$ and rash under breasts $(21.1 \%)$.

\section{Subjective complaints}

Comparing pre- and postoperative scores, there was a statistically significant reduction in symptom frequency on all items except for hand numbness. On a scale of one to 10 , neck pain and back pain improved from 4.1 to 1.2 and 5.5 to 1.7 , respectively. Preoperatively, $86 \%$ of women reported shoulder grooves, whereas postoperatively this decreased to $16 \%$. Three of the four items rated on the five-point Likert scale (clothing, sports, headaches) showed significant changes postoperatively $(\mathrm{P}<0.05)$. 


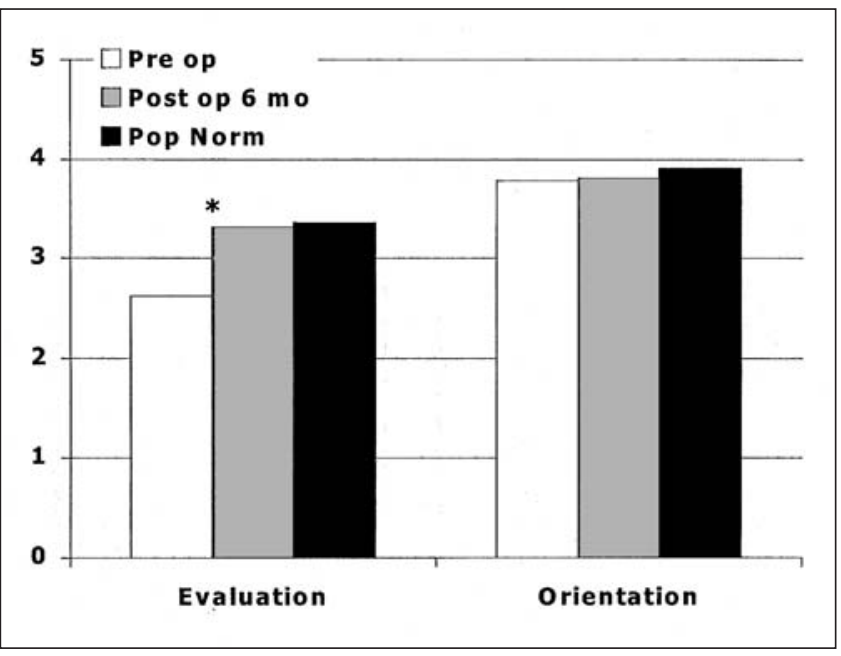

Figure 2) Multidimensional Body Self Relations Questionnaire scores before and after breast reduction $(n=41)$. *Statistically significant change as measured by paired t-test $(P=0.0000)$. mo Months; Pop Population; Post op Postoperative; Pre op Preoperative

\section{SF-36}

The pre- $(n=61)$ and postoperative $(n=38)$ SF-36 norm-based subscales and summary scales are indicated in Figure 1. On these norm-based scales, a score of 50 was the average score of the United States population, a score of 40 was one standard deviation below United States norms and a score of 60 was one standard deviation above United States norms. Statistically significant changes, as measured by unpaired $t$-test, were found for the subscales of physical functioning $(\mathrm{P}=0.0000)$, role-physical $(\mathrm{P}=0.019)$, bodily pain $(\mathrm{P}=0.0004)$ and vitality $(\mathrm{P}=0.033)$. Similar results were found with a paired $t$-test on the subset of patients for whom there were complete pre- and postoperative data $(n=34)$. The physical component summary scale also showed significant change following surgery $(\mathrm{P}=0.004)$, whereas the mental component summary scale did not $(\mathrm{P}=0.7896)$. Women with no change in their physical component summary scale $(n=8)$ had a mean resection weight of $452 \mathrm{~g}$ and those with a change in their physical component summary of greater than $10(n=7)$ had a mean resection weight of $753 \mathrm{~g}$. Despite this trend of greater improvements with greater weights of resection, there were no statistically significant relationships observed between change in the physical component summary scale and volume of resection $(\mathrm{P}=0.145)$, body surface area $(\mathrm{P}=0.190)$ or for $\mathrm{BMI}(\mathrm{P}=0.442)$.

\section{MBSRQ}

For the full cohort, 41 paired observations were available for analysis (Figure 2). A paired $t$-test indicated that appearance evaluation was significantly improved by surgery $(\mathrm{P}=0.0000)$ but appearance orientation was unaltered. The change in MBSRQ appearance evaluation remained clinically and statistically significant across all ranges of weight resection.

\section{DISCUSSION}

In the present study, additional support was added to the growing literature on the impact of breast reduction surgery on HRQL. Just as other researchers, we were able to document an improvement in several domains of quality of life and self-esteem. Existing self-administered questionnaires are sensitive to these changes. Two British studies used the SF-36 to study women with breast hypertrophy who underwent reduction mammaplasty (10-12). Klassen et al (10) documented that women with breast hypertrophy score lower on all domains than age-matched controls and that surgical intervention appreciably improves a woman's self-reported health state on all domains. In the second study (12), women showed improvements in all subscales of the SF-36, except for role-physical and role-emotional.

Other researchers have tried to develop algorithms to predict which women benefit most from reduction surgery. After studying 133 women, Miller et al (17) concluded that although breast reduction relieved preoperative symptoms in $93 \%$ of women, no predictive model could be developed. Cole and Shakespeare (18) found no correlation between BMI and symptom improvement, and concluded that all women gained similar improvements in quality of life. Similarly, in the present study, a statistically significant relationship could not be defined between weight of resected breast tissue, BMI or body surface area and improvement in symptoms, SF-36 physical component summary scale or MBSRQ appearance evaluation. Despite this growing evidence, many United States insurance carriers continue to rely on Schnur's sliding scale (5).

The impact of breast reduction surgery on self-esteem has been addressed by two studies, both using the Rosenberg self-esteem scale, a well validated instrument $(9,12,19)$. Likewise, these findings were confirmed with another well validated instrument, the MBSRQ.

The main weakness of our study was the limited number of study subjects with both pre- and postoperative data. This made it difficult to stratify patients into subgroups and still retain statistical power. The risk of a beta error is present because the present study cohort was small and there was not sufficient power to reliably test the statistical significance of any observed trends. A larger study cohort would be required to confirm or refute our findings. Just as in the study by Miller et al (17), a key predictor or formula was unable to be identified to help improve establishing objective criteria to guide insurance coverage of this surgery. Virtually all the women in the study gained benefits from the surgical intervention.

Future studies of a larger cohort of women with breast hypertrophy would be useful to address some of the issues raised by the present study. In addition, studying more women at the lower end of the spectrum and those with large breasts who are not presenting to the surgeon's office for consultation will help to shed more light on this patient population. Incorporating additional indicators of pain and patient preferences would also help to define more clearly the health burden that is carried by these women. 
ACKNOWLEDGEMENTS: The authors thank Dr John Sampalis for his assistance in the design and initial data analysis, and Dr Nancy Birkmeyer for the final data analysis. Also the study would not have been possible without the assistance of our residents, nursing and secretarial staff, and Marianna Boukas for study coordination and patient contact, and Hala Tamim for data entry. This work was funded by a Fraser Award from the Research Institute of the Royal Victoria Hospital, Montreal, Quebec.

\section{REFERENCES}

1. Schnur PL, Schnur DP, Petty PM, Hanson TJ, Weaver AL. Reduction mammaplasty: An outcome study. Plast Reconstr Surg 1997;100:875-83.

2. Gonzalez F, Walton RL, Shafer B, Matory WE Jr, Borah GL. Reduction mammaplasty improves symptoms of macromastia. Plast Reconstr Surg 1993;91:1270-6.

3. Goin MK, Gianini MH. The psychic consequences of a reduction mammaplasty. Plast Reconstr Surg 1977;59:530-4.

4. Goin MK. Psychological reactions to surgery of the breast. Clin Plast Surg 1982;9:347-54

5. Schnur PL, Hoehn JG, Ilstrup DM, Cahoy MJ, Chu C-P. Reduction mammaplasty: cosmetic or reconstructive procedure? Ann Plast Surg 1991;27:232-7.

6. Blomqvist L. Evaluation of a priority grouping system for patients undergoing reduction mammaplasty. Scand J Plast Reconstr Surg 1996;30:211-4.

7. World Health Organization. WHO as an Organization. <www.who.int/m/topicgroups/who_organization/en/index.html> Version current at June 28, 2001.

8. Epstein AM. The outcome movement - will it get us where we want to go? N Engl J Med 1990;323:266-70.
9. Weinberg M, Born T, Beaton D, Mahoney J. Functional outcome after breast reduction: A comparison of measurement outcome tools. Can J Plast Surg 1996;4:22. (Abst)

10. Klassen A, Fitzpatrick R, Jenkinson C, Goodacre T. Should breast reduction surgery be rationed? A comparison of the health status of patients before and after treatment: postal questionnaire survey. Brit Med J 1996;313:454-7.

11. Kerrigan CL, Sampalis J. Reduction mammaplasty: Impact on patient outcome. Can J Plast Surg 1997;5:39.

12. Shakespeare V, Cole RP. Measuring patient-based outcomes in a plastic surgery service: breast reduction surgical patients. Br J Plast Surg 1997;50:242-8.

13. Brown TA, Cash TF, Mikulka PJ. Attitudinal body-image assessment: factor analysis of the Body-Self Relations Questionnaire. J Pers Assess 1990;55:135-44.

14. Stewart AL, Hays RD, Ware JE. The MOS short-form general health survey. Reliability and validity in a patient population. Med Care 1988;26:724-35.

15. Tarlov AR, Ware JE, Greenfield S, et al. The medical outcomes study. An application of methods for monitoring the results of medical care. JAMA 1989;262:925-30.

16. Ware JE. SF-36 Physical and Mental Health Summary Scales: A User's Manual. Boston: Health Assessment Lab, New England Medical Center, 1994.

17. Miller AP, Zacher JB, Berggren RB, Falcone RE, Monk J. Breast reduction for symptomatic macromastia: can objective predictors for operative success be identified? Plast Reconstr Surg 1995;95:77-83.

18. Cole RP, Shakespeare V. Measuring patient-based outcomes in a plastic surgery service: breast reduction surgical patients. Br J Plast Surg 1998;51:79-80. (Lett)

19. Rosenberg M. Society and the adolescent self-image. Princeton: Princeton University Press, 1965:326. 